\title{
AGGREGATE PLANNING USING TRANSPORTATION METHOD: A CASE STUDY IN CABLE INDUSTRY
}

\author{
MstNazma Sultana ${ }^{1}$, Shohanuzzaman Shohan ${ }^{2}$, Fardim Sufian $^{3}$ \\ ${ }^{1}$ Lecturer, Department of Industrial Engineering and Management \\ Khulna University of Engineering \& Technology, Khulna-9203,BANGLADESH \\ ${ }^{2}$ Department of Industrial Engineering and Management \\ Khulna University of Engineering \& Technology, Khulna-9203,BANGLADESH \\ ${ }^{3}$ Department of Industrial Engineering and Management \\ Khulna University of Engineering \& Technology, Khulna-9203,BANGLADESH
}

\begin{abstract}
Aggregate planning is an analytical tool that proposes a strategy to meet demand according to the capacity constraints. In this paper, aggregate planning strategies are discussed and a special structure of transportation model is investigated for the aggregate planning purpose of "Bangladesh Cable Shilpa Ltd, Khulna”. For this transportation problem, all the unit costs, supplies, demands \& other values are taken from a case study. The forecasting demand values are determined using Single Exponential Smoothing Forecasting technique. Transportation model \& the Transportation algorithm is discussed in this paper. A real life unbalanced transportation problem is discussed and solved to bring the most efficient technique of reducing transportation and storage cost. Vogel Approximation Method (VAM) algorithm is also discussed \& used to determine the starting solution of the transportation model. Finally, TORA software is used to find the optimum cost by using transportation method.
\end{abstract}

\section{KEYWORDS}

Aggregate planning, Transportation model, Vogel Approximation Method(VAM), TORA transportation.

\section{INTRODUCTION}

Theaggregate planning problem is the production planning problem of an organization seeking to meet a varying pattern over a specific span of time. The capacity decisions can be made on three levels in an organization such as long term decision, intermediate term decision and short term decision. Many business organizations develop a business plan that encompasses both longterm and intermediate-term planning. Taking into account the organization's rules and policies,the aggregate planning creates strategies for the organization,create forecast data of demand for the organization's products or services.

Aggregate planning is basically a largerstyle of planning. Aggregate plannergenerally want to sidestepconcentrating on discrete product or service, except the organization focuses only one main product or service. Normally, they want to focus on a collection of parallel products or services. $^{[20]}$

Regular time production capacity, subcontracting capacity and overtime capacity are the different capacities which are normally used to manufacture products. Other possiblecapacities are also used if the regular time production capacity is not sufficient to manage with demands of DOI: $10.5121 /$ ijmvsc. 2014.5302 
different products. In this paper we considered a real life aggregate planning problem where the only affordable capacity options are regular capacity and overtime capacity.

\section{INPUTS TO AGGREGATE PLANNING}

Aggregate planning begins with a forecast of aggregate demand for the intermediate range. Then it is surveyed by a common plan to cope with the demand requirements for setting output and inventory levels or service capacities of finished goods.

Aggregate planners are concerned with the quality and the timing of expected demand. If total expected demand for the planning period is much different from available capacity over the same period, the major approach of planners will be to try to achieve a balance by altering capacity, demand or both. On the other hand, even if capacity and demand are approximately equal for the planning horizon as a whole, planning maystill be faced with problem of dealing with uneven demand within the planning interval. In some periods, expected demand may exceed projected capacity, in others expected demand may be less than projected capacity, and in some periods the two may be equal. The task of aggregate planners is to achieve rough equality of demand and capacity over the entire planning horizon. Moreover, planners are usually concerned with minimizing the cost of the aggregate plan, although plan, although cost is not the only consideration.

Effective aggregate planning requires good information. First,the available resources over the planning period must be known.Then, a forecast of expected demand must be available.Finally, planners must take into account any policies regarding changes in employment levels.Companies in the travel industry and some other industries often experience duplicate orders from customers who make multiple reservations but only intend to keep at most one of them.This makes capacity planning all the more difficult. ${ }^{[20]}$

\section{AGGREGATE PLANNING VARIABLES}

Aggregate planning or the development of a month by month intermediate range schedule for families of product service bundles, is based on an intermediate demand forecast. As the demand follows patterns, future demand is predictable, or "forecastable". However, the precision with which future demand can be predicted decreases the farther into the future one attempts to look.Depending on the planning system a business uses, this characteristic of forecasting may be more or less significant like the following systems:

* Make-to-stock system

* Make-to-order system

* Assemble-to-order system.

In a Make-to-stock system, the entire schedule is based on forecasted demand figures. In a Make-to-order system, manager have purchase orders in hand when they are planning, so they know the demand for products and services at least as forward as their processing lead times. Assemble-to-order systems are a combination of the make-to-stock and make-to-order approaches. Manufacture of customer orders are planned using assemblies and subassemblies that have been stocked in inventory.

The set of planning variables available to the aggregate planner is quite limited: it indicates only the inventory account, the monthly production rate, the size of the work force, and the extent of subcontracting. ${ }^{[4]}$ 
International Journal of Managing Value and Supply Chains (IJMVSC) Vol.5, No. 3, September 2014

\section{GENERAL AGGREGATE PLANNING STRATEGIES}

Aggregate planners may employ several strategies to meet expected customer demand like:

* Level production strategy

* Chase demand strategy

* Peak demand strategy

In a level production strategy, demand is met by altering only the inventory account. Demand is encountered by matching forecasted demand with the planned monthly production in thechase demand strategy, while the inventory level is kept fixed. In a peak demand strategy, particularly useful is service setting, capacity is varied to meet the highest level of demand at particular times. Aspects of these approaches can also be combines for particular use. ${ }^{[4]}$

The manufacturing industry which is investigated in this paper, Bangladesh Cable Shilpa limited, Khulna follows the chase demand strategy. In the chase demand strategy, changes in the use of overtime and the size of the work force are used to adjust monthly output to match changes in forecasted demand. Inventory level are held constant. This strategy is suitable for both manufacturing and service operations in which holding inventory or keeping a backlog is costly or impossible.

\section{METHODOLOGY}

Numerous techniques are offered to aid the assignment of aggregate planning. Generally, they fall into one of two categories: informal trial-error and mathematical techniques. In practice, informal techniques are more frequently used. However, a considerable amount of research has been devoted to mathematical techniques, and even though they are not as widely used, they often serve as a basis for comparing for effectiveness of alternative techniques for aggregate planning. Thus, it will be instructive to briefly examine them as well as the informal techniques. ${ }^{[20]}$

Aggregate Planning can be done using the following processes:

1. Determine demand for each period.

2. Determine capacities (Regular time, overtime) for each period.

3. Identify Organization policies that are relevant(example: safety store can be maintained of at least $5 \%$ of total demand, a stable workforce can also be kept).

4. Determine unit cost for regular time, overtime, holding inventories, back ordersand other relevant costs.

5. Create and improve alternative procedures and calculate the total cost for each individual procedure.

6. If acceptable plans appear, choose the one that satisfies objective the most. Otherwise, return to step 5 .

\subsection{Determining demand for each period}

Aggregate planning starts with a forecast of aggregate demand. The forecasting values can be achieved using various techniques for time series data. Historical data is used as the basis of approximating future result in the Time series methods. Most popular techniques are:

- Moving average

- Exponential smoothing

- Weighted moving average

- Kalman filtering 
In this paper the Single Exponential Smoothing is used to determine the forecasted demand data though moving average and exponential smoothing system are also used but the single exponential smoothing gives the most accurate results. Single exponential smoothing gives the smooth statistics and the smooth graph results in a better understanding of forecasting data. As a result the decision making process becomes a lot easier.

\subsubsection{Single exponential smoothing}

Let us consider the constant time series model

$$
\chi_{\mathrm{t}}=\mathrm{a}+\varepsilon_{\mathrm{t}}
$$

Where $\varepsilon_{t}$ is a random error component. We shall assume that $\mathrm{E}(\boldsymbol{\varepsilon} t)=0, . \mathrm{V}(\boldsymbol{\varepsilon} t)=\sigma_{\varepsilon}^{2,}$ and that the errors are independently distributed random variables. Suppose, we wish to estimate a such that the following sum of weighted squared residuals is minimized:

$$
\mathrm{SS}_{\mathrm{E}}=\sum_{i=1}^{n} \beta^{\mathrm{T}-\mathrm{t}}\left(\chi_{\mathrm{t}}-\hat{\mathrm{a}}\right)^{2}, \quad 0<\beta<1
$$

Where $\beta^{T-t}$ is the weight given to the $\mathrm{r}^{\text {th }}$ residual. Note that the weight decrease with the age of the data. Proceeding as before, â must satisfy.

Or

$$
\frac{d S S_{E}}{d \hat{\mathrm{a}}}=-2 \sum_{T=1}^{T} \beta^{\mathrm{T}-\mathrm{t}}\left(\chi_{\mathrm{t}}-\hat{\mathrm{a}}\right)=0
$$

Solving for â we obtain

$$
\hat{\mathrm{a}} \sum_{T=1}^{T} \beta^{\mathrm{T}-\mathrm{t}}=\sum_{T=1}^{T} \beta^{\mathrm{T}-\mathrm{t}} \chi_{\mathrm{t}}
$$

Subtracting $\mathrm{S}_{\mathrm{T}-1}$ from $\mathrm{S}_{\mathrm{T}}$,

$$
\hat{\mathrm{a}}=\left(\frac{1-\beta}{1-\beta^{T}}\right) \sum_{T=1}^{T} \beta^{\mathrm{T}-\mathrm{t}} \chi_{\mathrm{t}} \equiv \mathrm{S}_{\mathrm{T}}
$$

$$
\mathrm{S}_{\mathrm{T}}=\frac{1}{\left(1-\beta^{T}\right)}\left[(1-\beta) \chi_{\mathrm{T}+} \beta\left(1-\beta^{\mathrm{T}-1}\right) \mathrm{S}_{\mathrm{T}-1}\right]
$$

Let $\alpha=1-\beta$ and assume that $\mathrm{T}$ is large so that $\beta^{\mathrm{T}} \equiv 0$.Then,

$$
\mathrm{S}_{\mathrm{T}=} \alpha \mathrm{x}_{\mathrm{T}}+(1-\alpha) \mathrm{S}_{\mathrm{T}-1}
$$

The operation is called simple exponential smoothing, and $\mathrm{S}_{\mathrm{T}}$ is called smoothed value or smoothed statistic. Here, constant $\alpha$ is referred as the smoothing constant. ${ }^{[6]}$

\subsection{Aggregate planning using the transportation method}

There exist $m$ origin, with the $i$ th origin possessing $a_{\mathrm{i}}$ units, and $\mathrm{n}$ destinations, with the $j$ th destination requiring $b_{j}$ units. It is not required that $\mathrm{m}$ be equal to $\mathrm{n}$, but total of the units available at $m$ must be equal of the total of the requirements in the destination. Associated with the allocation of one unit from the $i$ th origin to the $j$ th destination is a certain effectiveness coefficient, $e_{\mathrm{ij} .}$. If $x_{\mathrm{ij}}$ is the number of the total units' allocation from the $i$ th to the $j$ th, the transportation problem may be stated mathematically as that of optimizing the effectiveness function

$$
E=\sum_{i=1}^{m} \sum_{i=1}^{n} e i j x i j
$$

Subject to

$$
\sum_{i=1}^{m} x i j=b j j=1,2, \ldots \ldots, n
$$


Where

$$
\sum_{j=1}^{n} x i j=a j i=1,2, \ldots \ldots, m
$$

$$
\sum_{i=1}^{m} a i=\sum_{j=1}^{n} b j
$$

Optimization will require either minimization or maximization, depending on the measure of effectiveness involved. The decision maker has under his control the allocation matrix, $x_{\mathrm{ij} .}$ Not directly under his control is the matrix of effectiveness coefficients, $e \mathrm{ij}^{[2]}$

It is possible to formulate aggregate planning problem in such a way that if the solution exist somewhere, it can be shown to be optimal. Thus, in contrast with the preceding trial-error methods we now have the assurance that the "best" production plan is prepared. One technique used for this purpose is the transportation method in linear programming. This approach allows for the use of regular production, overtime, inventory, back-ordering, and subcontracting. ${ }^{[21]}$

In order to employ the transportation method we must formulate the aggregate planning problem so that

1. Productive capacity (supply) and demand are expressed in the same units.

2. Total capacity for the planning horizon equals total forecast demand. If this condition is not met, we can create artificial capacity sources or demand requirements, at zero cost per unit, so that the system is balanced.

3. All cost relationships are treated as being linear.

L.H. Bowman has indicated a Transportation Problem approach to aggregate planning. The model, considering a combination of only the three strategies of (i) regular time production, (ii) overtime production, and (iii) inventory, is presented in the following figure. It is for four periods of time.

Where,

$>\mathrm{M}_{\mathrm{i}}=$ Regular time production (Maximum) during period $\mathrm{i}$

$>\mathrm{Y}_{\mathrm{i}}=$ Overtime production (Maximum) during period $\mathrm{i}$

$>\mathrm{D}_{\mathrm{i}}=$ Demand during period $\mathrm{i}$

$>\mathrm{I}_{\mathrm{i}}=$ Inventory at the end of period $\mathrm{i}$

$>\mathrm{r}=$ Regular time cost of production, per unit

$>\mathrm{v}=$ Over time cost of production, per unit

$>\mathrm{c}=$ Cost of carrying the inventory per unit per period

$>\mathrm{L}=$ Total slack

$>\mathrm{X}=$ Very high cost, so that those cells are forbidden. 
International Journal of Managing Value and Supply Chains (IJMVSC) Vol.5, No. 3, September 2014

\begin{tabular}{|c|c|c|c|c|c|c|}
\hline \multirow{2}{*}{ Availabilities } & \multicolumn{4}{|c|}{ Period } & \multirow{2}{*}{ Inventory } & \multirow{2}{*}{ Slack } \\
\hline & 1 & 2 & 3 & 4 & & \\
\hline $\mathrm{I}_{0}$ & 0 & c & $2 \mathrm{c}$ & $3 c$ & $4 c$ & 0 \\
\hline $\mathrm{M}_{1}$ & $\mathrm{r}$ & $r+c$ & $\mathrm{r}+2 \mathrm{c}$ & $\mathrm{r}+3 \mathrm{c}$ & $\mathrm{r}+4 \mathrm{c}$ & 0 \\
\hline $\mathrm{Y}_{1}$ & $\overline{\mathrm{v}}$ & $\overline{v+c}$ & $\mathrm{v}+2 \mathrm{c}$ & $\bar{v} \mathrm{v}+3 \mathrm{c}$ & $\bar{V}+4 c$ & 0 \\
\hline $\mathrm{M}_{2}$ & $\overline{\mathrm{X}}$ & $\overline{\mathrm{r}}$ & $\mathrm{r}+\mathrm{c}$ & $\mathrm{r}+2 \mathrm{c}$ & $\mathrm{r}+3 \mathrm{c}$ & 0 \\
\hline $\mathrm{Y}_{2}$ & $\overline{\mathrm{X}}$ & $\overline{\mathrm{v}}$ & $\mathrm{v}+\mathrm{c}$ & $\mathrm{v}+2 \mathrm{c}$ & $\mathrm{v}+3 \mathrm{c}$ & 0 \\
\hline $\mathrm{M}_{3}$ & $\overline{\mathrm{X}}$ & $\overline{\mathrm{X}}$ & $\overline{\mathrm{r}}$ & $\mathrm{r}+\mathrm{c}$ & $\mathrm{r}+2 \mathrm{c}$ & 0 \\
\hline $\mathrm{Y}_{3}$ & $\overline{\mathrm{X}}$ & $\overline{\mathrm{X}}$ & $\overline{\mathrm{v}}$ & $\mathrm{v}+\mathrm{c}$ & $\mathrm{v}+2 \mathrm{c}$ & 0 \\
\hline $\mathrm{M}_{4}$ & $\mathrm{X}$ & $\mathrm{X}$ & $\mathrm{X}$ & $\mathrm{r}$ & $r+c$ & 0 \\
\hline $\mathrm{Y}_{4}$ & $\overline{\bar{X}}$ & $\overline{\mathrm{X}}$ & $\overline{\mathrm{X}}$ & $\overline{\mathrm{v}}$ & $\mathrm{v}+\mathrm{c}$ & 0 \\
\hline Requirements & $\mathrm{D}_{1}$ & $\mathrm{D}_{2}$ & $\mathrm{D}_{3}$ & $\mathrm{D}_{4}$ & $\mathrm{I}_{\mathrm{n}}$ & L \\
\hline
\end{tabular}

This model can be extended to consider several products separately. Each product will have a different requirements column, whereas the 'availabilities' rows would remain the same. A suitable unit of production can be chosen which could be common to all products. ${ }^{[10]}$

\subsection{Unbalanced transportation problems}

A problem in the transportation model occurring quite frequently in real-life is total demand and total supply is not always equal. These situation can be controlledappropriately by the previous solution procedures if the term "dummy sources "or "dummy destinations" is introduced first. Whentotal supplycapacity is larger than the demand, a dummy destinationcan be created along with the demandwhich will be precisely equal to the left-over or surplus. If total demand is greater than total supply, we introduce a dummy source with a supply equal to the excess of demand over supply. Delivery cost coefficients are allocatedwith a value of zero to each dummy location in both cases as no delivery would actually be produced from a dummy source or to a dummy factory. Each unit of productallocated to the dummy destination signifythat the capacity is excess, and each unit allocated to the dummy source represent that the demand is still not fulfilled. ${ }^{[3]}$

In Bangladesh Cable Shilpa limited, Khulna,after statistical analysis it was observed that in most of the time period for the last 2 year, the demand for copper cable is greater than supply. So this situation is discussed below.

\subsubsection{Total supply smaller than total demand}

This type of condition takes place when the total supply is smaller than total demand. This means that customers require less of a product than the Manufacturer or Producer Company can provide. In this situation we have to add a dummy row which will represent the dummy demand. 


\begin{tabular}{|c|c|c|c|c|c|c|c|c|c|}
\hline From $\mathrm{To}$ & \multicolumn{2}{|l|}{ A } & \multicolumn{2}{|c|}{ B } & \multicolumn{2}{|c|}{ C } & \multicolumn{2}{|c|}{$\begin{array}{l}\text { Dummy } \\
\text { Demand }\end{array}$} & $\begin{array}{l}\text { Factory } \\
\text { capacity }\end{array}$ \\
\hline $\mathrm{D}$ & & 5 & & 6 & & 7 & & 0 & 250 \\
\hline $\mathrm{E}$ & & 8 & & 12 & & 11 & & 0 & \\
\hline $\mathrm{F}$ & & 9 & & 7 & & 8 & & 0 & \\
\hline $\begin{array}{c}\text { Total } \\
\text { Demand }\end{array}$ & 300 & & 20 & & 2 & & 13 & & 850 \\
\hline
\end{tabular}

After adding the extra row the organization would have a supply amount which is precisely equal to the difference between total demand of that unit time and actual supply capacity. The delivery costs from the dummy source to each destination will be equal to zero.

\subsection{Determination of the starting solution}

The general definition of the transportation model requires that this experiment results in one dependent equation, which means that the transportation model has only $m+n-1$ independent equations. Thus, as in the simplex method, a starting basic solution must include $m+n-1$ basics variables.

Normally, if the transportation model is formulated as a simplex tableau, if would be necessary to utilize artificial variables to secure a starting basic solution. However, when the transportation tableau is used, a starting basic feasible solution can be obtained easily and directly. We present a procedure called the Vogel's approximationmethod for this purpose. Two other procedures, called least-cost method and northwest corner rule can also be used .These procedures usually provide better starting solutions in the sense that the associated values of the objective function are smaller. ${ }^{[13]}$

\subsection{Vogel's Approximation Method (VAM)}

The procedure is simple and fast by comparison. Its advocates claim that it will give an optimal allocation for a majority of problems and that the approximation is very good for the remainder. In some applications, the final result of this approximation method may be accepted as is. In others it might be desirable to apply the optimality test and then iterate toward an optimal solution if needed. Normally, this scheme is used to find an initial solution so that the total number of iterations can be reduced which is required by the conventional method.

Vogel's Approximation Method (VAM)takes into account total costs related with every route alternative so that it cantackles the problem of finding a better preliminary solution. The Northwest corner rule is unable to act in such a way. For the implementation of VAM, each row and column the penalty is computed and it is checked if the second best route is deliveredin the place of least-cost route, which is preferred.

To identify theprimary VAM solution, we can use a six step process: ${ }^{[3]}$

VAM Step 1.Difference between the two lowest unit delivery costs is first determined for each row and column of the traditional transportation table. Thedifference between the distribution 
costs are referred by these numbers on the most optimum route in the row or column and the next optimum route in the row or column.

For instance, here in row $\mathrm{E}$ the three transportation costs are $\$ 8, \$ 4$, and $\$ 3$ are given. The two lowest costs are $\$ 4$ and $\$ 3$, so their difference is $\$ 1$.

VAM Step 2.Then the greatest opportunitycost which means the differenceis identifiedin the row or column.

According to the previous example column A is selected, which has a difference of 3 here.

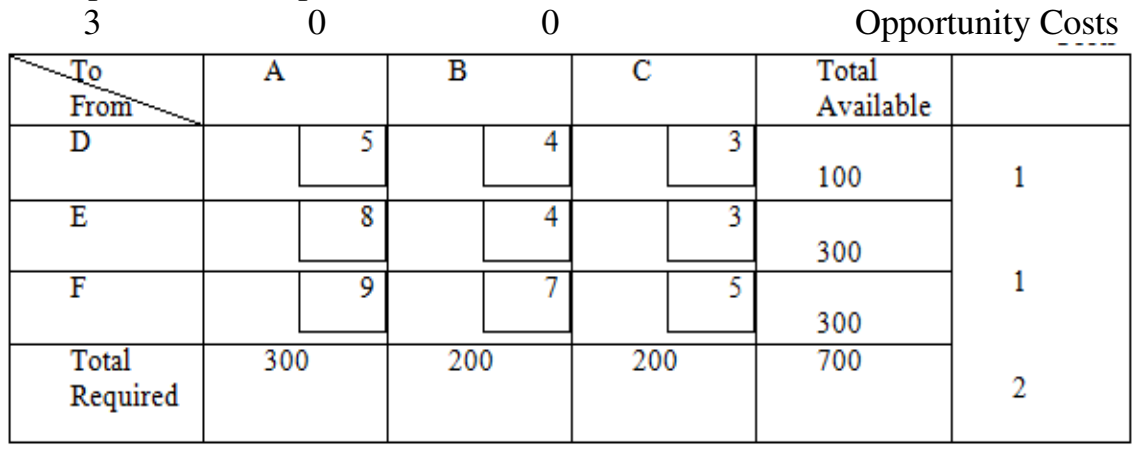

VAM Step 3.The box with lowest-cost in the row or column will be selected after assigning as many units as possible.

As it can be seen in the column A that lowest-cost route here is D-A.

VAM Step 4.After completely fulfilling by the assignment, that row or column will be eliminated. This can be done by placing $X$ 's in appropriate square.

At the D-B or D-C routes it is not recommended to assign any further assignment..

VAM Step 5.The differences between the costs should be re-compute for the transportation table, the omitting rows or columns should be eliminated in the previous step.

The change in A's, B's and C's differences are shown here and the row of D is removed, and the difference between E's and F's remain as previous.

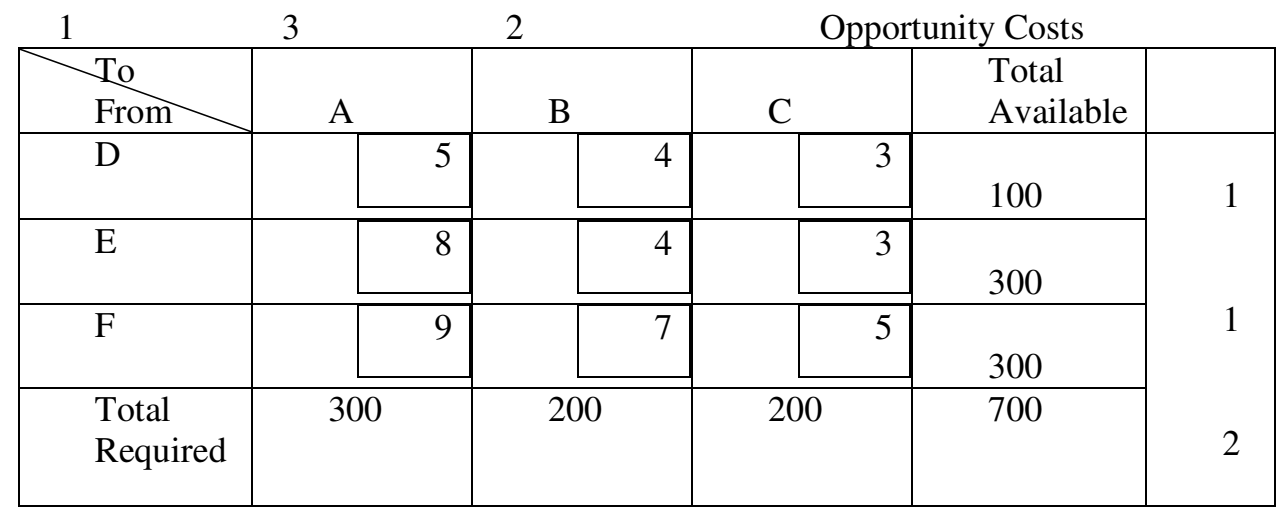

VAM Step 6.For the last step in this process step 2 will be returned for the remaining rows and columns and all the steps will be repeatedso that an initial feasible solution can be found.

Here still200 units to the lowest-cost box in column B exist. X is placed in the F-B square so that it can be eliminated as B's requirements are still unfulfilled. 


\begin{tabular}{|c|c|c|c|c|c|c|c|c|}
\hline From & \multicolumn{2}{|l|}{ A } & \multicolumn{2}{|l|}{ B } & \multicolumn{2}{|l|}{$\mathrm{C}$} & $\begin{array}{l}\text { Total } \\
\text { Available }\end{array}$ & \\
\hline D & & 5 & 2 & 4 & 2 & 3 & 100 & 1 \\
\hline & 00 & & & & & & & \\
\hline E & & 8 & & 4 & & 3 & 300 & 5 \\
\hline & & & 0 & & & & & \\
\hline $\bar{F}$ & & 9 & 2 & 7 & & 5 & 300 & 4 \\
\hline $\begin{array}{l}\text { Total } \\
\text { Required }\end{array}$ & 300 & & 200 & & 200 & & 700 & \\
\hline
\end{tabular}

\section{CASE STUDY}

To make a real life aggregate planning according the above process, actual demand data was taken from Bangladesh Cable Shilpa limited, Khulna. This organization produces telephone copper cable since 1967.

After collecting the actual demand data for the last 9 month of the previous year we made the forecasting demand for this year's last 9 period using single exponential smoothing forecasting technique which has been discussed briefly in previous portion. TORA software is used to get the numeric values for the forecasting demand. Here, the value of smoothing constant is .20.

Thus, the demand for eight period of this year in the cable company is collected. The monthly capacity of the production department is $41600 \mathrm{~km}$ in the Regular time period and $20800 \mathrm{~km}$ in the Overtime period. The cost of production of per unit of copper cable is 5 TK in Regular time period and 7.25 TK in overtime period. The inventory cost per month per unit is .25 TK. All these data are put in the transportation table. Backordering is allowed with a greater cost of $3 \mathrm{TK}$ per unit per month. As the transportation algorithm states, the demand and capacity have to be equal in the transportation table, the dummy demand equals the demand and capacity. All these data were delivered in the TORA software as input.

Table 1. Forecasting Demand from Case Study

\begin{tabular}{|c|c|c|}
\hline Period & Actual Demand & Forecasting Demand $(\alpha=.20)$ \\
\hline 1 & 39773.00 & ----------- \\
\hline 2 & 36289.00 & 39773.00 \\
\hline 3 & 55588.00 & 39076.19 \\
\hline 4 & 45891.00 & 42378.56 \\
\hline 5 & 55056.00 & 43081.05 \\
\hline 6 & 32974.00 & 45476.04 \\
\hline 7 & 57803.00 & 42975.63 \\
\hline 8 & 33792.00 & 45941.11 \\
\hline 9 & 63321.00 & 43511.29 \\
\hline
\end{tabular}


International Journal of Managing Value and Supply Chains (IJMVSC) Vol.5, No. 3, September 2014

\begin{tabular}{|c|c|c|c|c|c|c|c|c|c|c|c|}
\hline \multicolumn{2}{|c|}{ Period } & \multirow{2}{*}{$\begin{array}{c}1 \\
D 1\end{array}$} & \multirow{2}{*}{$\begin{array}{r}2 \\
D 2\end{array}$} & \multirow{2}{*}{$\begin{array}{r}3 \\
D 3\end{array}$} & \multirow{2}{*}{\begin{tabular}{|l}
4 \\
$D 4$
\end{tabular}} & \multirow{2}{*}{$\begin{array}{rr} & 5 \\
D 5 & \end{array}$} & \multirow{2}{*}{$\begin{array}{c}6 \\
D 6\end{array}$} & \multirow{2}{*}{$\begin{array}{r}7 \\
D 7\end{array}$} & \multirow{2}{*}{$\begin{array}{c}8 \\
D s\end{array}$} & \multirow{2}{*}{\begin{tabular}{|l} 
\\
Dumm \\
y
\end{tabular}} & \multirow{2}{*}{$\begin{array}{l} \\
\text { Sup } \\
\text { ply }\end{array}$} \\
\hline & & & & & & & & & & & \\
\hline S1 & Rl & 5 & 5.25 & 5.5 & \begin{tabular}{|l|l|}
5.75 \\
\end{tabular} & \begin{tabular}{|l|}
6 \\
\end{tabular} & 6.25 & \begin{tabular}{|l|}
6.5 \\
\end{tabular} & 6.75 & 0 & 41.6 \\
\hline S2 & 01 & 7.25 & 7.5 & 7.75 & \begin{tabular}{|l|}
8 \\
\end{tabular} & \begin{tabular}{|l}
8.25 \\
\end{tabular} & 8.5 & \begin{tabular}{|l|}
8.75 \\
\end{tabular} & 9 & 0 & 20.8 \\
\hline S3 & R2 & 8 & 5 & 5.25 & 5.5 & \begin{tabular}{|l|}
5.75 \\
\end{tabular} & 6 & \begin{tabular}{|l|}
6.25 \\
\end{tabular} & 6.5 & 0 & 41.6 \\
\hline S4 & 02 & 10.25 & 7.25 & 7.5 & \begin{tabular}{|l}
7.75 \\
\end{tabular} & \begin{tabular}{|l}
8 \\
\end{tabular} & 8.25 & \begin{tabular}{|l|}
8.5 \\
\end{tabular} & 8.75 & 0 & 20.8 \\
\hline S5 & R3 & 11 & 8 & 5 & \begin{tabular}{|l}
5.25 \\
\end{tabular} & 5.5 & 5.75 & 6 & 6.25 & 0 & 41.6 \\
\hline S6 & 03 & 13.25 & 10.25 & 7.25 & \begin{tabular}{|l|}
7.5 \\
\end{tabular} & \begin{tabular}{|l}
7.75 \\
\end{tabular} & 8 & 8.25 & 8.5 & 0 & 20.8 \\
\hline S7 & R4 & 14 & 11 & 8 & 5 & \begin{tabular}{|l|}
5.25 \\
\end{tabular} & 5.5 & 5.75 & 6 & 0 & 41.6 \\
\hline S8 & 04 & 16.25 & 13.25 & 10.25 & \begin{tabular}{|l|}
7.25 \\
\end{tabular} & \begin{tabular}{|l|}
7.5 \\
\end{tabular} & 7.75 & 8 & 8.25 & 0 & 20.8 \\
\hline S9 & R5 & 17 & 14 & 11 & 8 & 5 & 5.25 & 5.5 & 5.75 & 0 & 41.6 \\
\hline S10 & 05 & 19.25 & 16.25 & 13.25 & 10.25 & \begin{tabular}{|l|}
7.25 \\
\end{tabular} & 7.5 & 7.75 & 8 & 0 & 20.8 \\
\hline S11 & R6 & 20 & 17 & 14 & 11 & 8 & 5 & 5.25 & 5.5 & 0 & 41.6 \\
\hline S12 & 06 & 22.25 & 19.25 & 16.25 & 13.25 & 10.25 & 7.25 & 7.5 & 7.75 & 0 & 20.8 \\
\hline $\mathrm{S} 13$ & R7 & 23 & 20 & 17 & 14 & \begin{tabular}{|l|}
11 \\
\end{tabular} & 8 & 5 & 5.25 & 0 & 41.6 \\
\hline S14 & 07 & 25.25 & 22.25 & 19.25 & 16.25 & 13.25 & 10.25 & 7.25 & 7.5 & 0 & 20.8 \\
\hline S15 & R8 & 26 & 23 & 20 & 17 & 14 & 11 & 8 & 5 & 0 & 41.6 \\
\hline S16 & 08 & 28.25 & 25.25 & 22.25 & 19.25 & 16.25 & 13.25 & 10.25 & 7.25 & 0 & 20.8 \\
\hline DEA & IND & 39.8 & 39.0 & 42.3 & 43.0 & 45.5 & 42.9 & 45.9 & 43.5 & 150 & \\
\hline
\end{tabular}

Here,

$\mathrm{S}_{\mathrm{i}}=$ Source Number

$\mathrm{R}_{\mathrm{i}}=$ Regular time cost per unit.

$\mathrm{O}_{\mathrm{i}}=$ Overtime cost unit per unit.

$\mathrm{D}_{\mathrm{i}}=$ Destination Number

$\mathrm{I}=1,2,3, \ldots$ ..,n.

\section{RESULT}

Using the TORA software, after including all the data the problem was solved using the Vogel's approximation as the starting solution as shown below: 


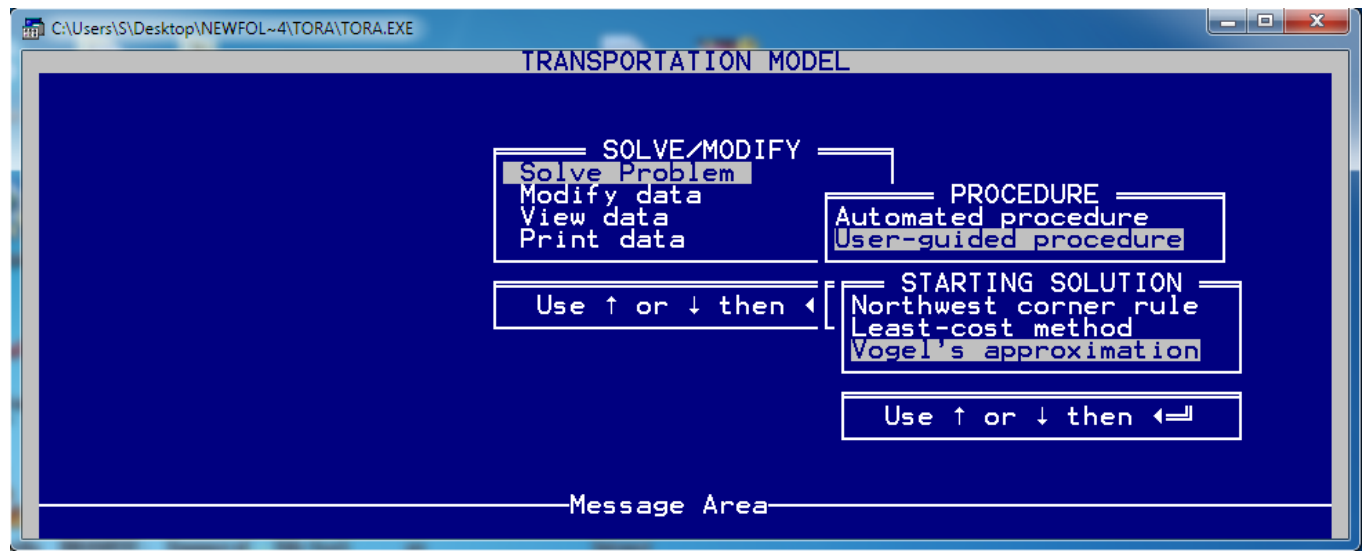

Figure 1: TORA software user interface

The TORA software gives the following result as output:

\section{OPTIMUM TRANSPORTATION SOLUTION}

Title: aggregate planning problem

Size: $(16 * 9)$

Final iteration no: 4

Total cost: 1715.00

\begin{tabular}{|c|c|c|c|c|}
\hline From & To & Amount & Unit Cost & Route Cost \\
\hline \multirow{9}{*}{$\mathrm{S} 1$} & D1 & 39 & 5.00 & 195.00 \\
\hline & D2 & 2 & 5.25 & 10.50 \\
\hline & D3 & 0 & 5.50 & 0.00 \\
\hline & D4 & 0 & 5.75 & 0.00 \\
\hline & D5 & 0 & 6.00 & 0.00 \\
\hline & D6 & 0 & 6.25 & 0.00 \\
\hline & D7 & 0 & 6.50 & 0.00 \\
\hline & D8 & 0 & 6.75 & 0.00 \\
\hline & D9 Dummy & 0 & 0.00 & 0.00 \\
\hline From & To & Amount & Unit Cost & Route Cost \\
\hline \multirow{9}{*}{$\mathrm{S} 2$} & D1 & 0 & 7.25 & 0.00 \\
\hline & D2 & 0 & 7.50 & 0.00 \\
\hline & D3 & 0 & 7.75 & 0.00 \\
\hline & D4 & 0 & 8.00 & 0.00 \\
\hline & D5 & 0 & 8.25 & 0.00 \\
\hline & D6 & 0 & 8.50 & 0.00 \\
\hline & D7 & 0 & 8.75 & 0.00 \\
\hline & D8 & 0 & 9.00 & 0.00 \\
\hline & D9 Dummy & 20 & 0.00 & 0.00 \\
\hline & D1 & 0 & 8.00 & 0.00 \\
\hline & D2 & 37 & 5.00 & 185.00 \\
\hline
\end{tabular}


International Journal of Managing Value and Supply Chains (IJMVSC) Vol.5, No. 3, September 2014

\begin{tabular}{|c|c|c|c|c|}
\hline \multirow{7}{*}{$\mathrm{S} 3$} & D3 & 4 & 5.25 & 21.00 \\
\hline & D4 & 0 & 5.50 & 0.00 \\
\hline & D5 & 0 & 5.75 & 0.00 \\
\hline & D6 & 0 & 6.00 & 0.00 \\
\hline & D7 & 0 & 6.25 & 0.00 \\
\hline & D8 & 0 & 6.50 & 0.00 \\
\hline & D9 Dummy & 0 & 0.00 & 0.00 \\
\hline \multirow{9}{*}{$\mathrm{S} 4$} & D1 & 0 & 10.25 & 0.00 \\
\hline & $\mathrm{D} 2$ & 0 & 7.25 & 0.00 \\
\hline & $\mathrm{D} 3$ & 0 & 7.50 & 0.00 \\
\hline & D4 & 0 & 7.75 & 0.00 \\
\hline & D5 & 0 & 8.00 & 0.00 \\
\hline & D6 & 0 & 8.25 & 0.00 \\
\hline & D7 & 0 & 8.50 & 0.00 \\
\hline & D8 & 0 & 8.75 & 0.00 \\
\hline & D9 Dummy & 20 & 0.00 & 0.00 \\
\hline \multirow{9}{*}{ S5 } & D1 & 0 & 11.00 & 0.00 \\
\hline & D2 & 0 & 8.00 & 0.00 \\
\hline & D3 & 38 & 5.00 & 190.00 \\
\hline & D4 & 3 & 5.25 & 15.75 \\
\hline & D5 & 0 & 5.50 & 0.00 \\
\hline & D6 & 0 & 5.75 & 0.00 \\
\hline & D7 & 0 & 6.00 & 0.00 \\
\hline & D8 & 0 & 6.25 & 0.00 \\
\hline & D9 Dummy & 0 & 0.00 & 0.00 \\
\hline \multirow{9}{*}{ S6 } & D1 & 0 & 13.25 & 0.00 \\
\hline & D2 & 0 & 10.25 & 0.00 \\
\hline & D3 & 0 & 7.25 & 0.00 \\
\hline & D4 & 0 & 7.50 & 0.00 \\
\hline & D5 & 0 & 7.75 & 0.00 \\
\hline & D6 & 0 & 8.00 & 0.00 \\
\hline & D7 & 0 & 8.25 & 0.00 \\
\hline & D8 & 0 & 8.50 & 0.00 \\
\hline & D9 Dummy & 20 & 0.00 & 0.00 \\
\hline \multirow{9}{*}{ S7 } & D1 & 0 & 14.00 & 0.00 \\
\hline & D2 & 0 & 11.00 & 0.00 \\
\hline & D3 & 0 & 8.00 & 0.00 \\
\hline & D4 & 40 & 5.00 & 200.00 \\
\hline & D5 & 1 & 5.25 & 5.25 \\
\hline & D6 & 0 & 5.50 & 0.00 \\
\hline & D7 & 0 & 5.75 & 0.00 \\
\hline & D8 & 0 & 6.00 & 0.00 \\
\hline & D9 Dummy & 0 & 0.00 & 0.00 \\
\hline \multirow[b]{7}{*}{ S8 } & D1 & 0 & 16.25 & 0.00 \\
\hline & D2 & 0 & 13.25 & 0.00 \\
\hline & D3 & 0 & 10.25 & 0.00 \\
\hline & D4 & 0 & 7.25 & 0.00 \\
\hline & D5 & 0 & 7.50 & 0.00 \\
\hline & D6 & 0 & 7.75 & 0.00 \\
\hline & D7 & 0 & 8.00 & 0.00 \\
\hline
\end{tabular}


International Journal of Managing Value and Supply Chains (IJMVSC) Vol.5, No. 3, September 2014

\begin{tabular}{|c|c|c|c|c|}
\hline & D8 & 0 & 8.25 & 0.00 \\
\hline & D9 Dummy & 20 & 0.00 & 0.00 \\
\hline \multirow{9}{*}{ S9 } & D1 & 0 & 17.00 & 0.00 \\
\hline & $\mathrm{D} 2$ & 0 & 14.00 & 0.00 \\
\hline & D3 & 0 & 11.00 & 0.00 \\
\hline & D4 & 0 & 8.00 & 0.00 \\
\hline & D5 & 41 & 5.00 & 205.00 \\
\hline & D6 & 0 & 5.25 & 0.00 \\
\hline & D7 & 0 & 5.50 & 0.00 \\
\hline & D8 & 0 & 5.75 & 0.00 \\
\hline & D9 Dummy & 0 & 0.00 & 0.00 \\
\hline \multirow{9}{*}{$\mathrm{S} 10$} & D1 & 0 & 19.25 & 0.00 \\
\hline & $\mathrm{D} 2$ & 0 & 16.25 & 0.00 \\
\hline & D3 & 0 & 13.25 & 0.00 \\
\hline & D4 & 0 & 10.25 & 0.00 \\
\hline & D5 & 3 & 7.25 & 21.75 \\
\hline & D6 & 0 & 7.50 & 0.00 \\
\hline & D7 & 0 & 7.75 & 0.00 \\
\hline & D8 & 0 & 8.00 & 0.00 \\
\hline & D9 Dummy & 17 & 0.00 & 0.00 \\
\hline \multirow{9}{*}{ S11 } & D1 & 0 & 20.00 & 0.00 \\
\hline & $\mathrm{D} 2$ & 0 & 17.00 & 0.00 \\
\hline & D3 & 0 & 14.00 & 0.00 \\
\hline & $\mathrm{D} 4$ & 0 & 11.00 & 0.00 \\
\hline & D5 & 0 & 8.00 & 0.00 \\
\hline & D6 & 41 & 5.00 & 205.00 \\
\hline & D7 & 0 & 5.25 & 0.00 \\
\hline & D8 & 0 & 5.50 & 0.00 \\
\hline & D9 Dummy & 0 & 0.00 & 0.00 \\
\hline \multirow{9}{*}{$\mathrm{S} 12$} & D1 & 0 & 22.25 & 0.00 \\
\hline & D2 & 0 & 19.25 & 0.00 \\
\hline & D3 & 0 & 16.25 & 0.00 \\
\hline & D4 & 0 & 13.25 & 0.00 \\
\hline & D5 & 0 & 10.25 & 0.00 \\
\hline & D6 & 1 & 7.25 & 7.25 \\
\hline & D7 & 0 & 7.50 & 0.00 \\
\hline & D8 & 0 & 7.75 & 0.00 \\
\hline & D9 Dummy & 19 & 0.00 & 0.00 \\
\hline \multirow{12}{*}{ S13 } & D1 & 0 & 23.00 & 0.00 \\
\hline & $\mathrm{D} 2$ & 0 & 20.00 & 0.00 \\
\hline & D3 & 0 & 17.00 & 0.00 \\
\hline & D4 & 0 & 14.00 & 0.00 \\
\hline & D5 & 0 & 11.00 & 0.00 \\
\hline & D6 & 0 & 8.00 & 0.00 \\
\hline & D7 & 41 & 5.00 & 205.00 \\
\hline & D8 & 0 & 5.25 & 0.00 \\
\hline & D9 Dummy & 0 & 0.00 & 0.00 \\
\hline & D1 & 0 & 25.25 & 0.00 \\
\hline & D2 & 0 & 22.25 & 0.00 \\
\hline & D3 & 0 & 19.25 & 0.00 \\
\hline
\end{tabular}


International Journal of Managing Value and Supply Chains (IJMVSC) Vol.5, No. 3, September 2014

\begin{tabular}{|c|c|c|c|c|}
\hline \multirow{6}{*}{ S14 } & D4 & 0 & 16.25 & 0.00 \\
\hline & D5 & 0 & 13.25 & 0.00 \\
\hline & D6 & 0 & 10.25 & 0.00 \\
\hline & D7 & 4 & 7.25 & 29.00 \\
\hline & D8 & 0 & 7.50 & 0.00 \\
\hline & D9 Dummy & 16 & 0.00 & 0.00 \\
\hline \multirow{9}{*}{ S15 } & D1 & 0 & 26.00 & 0.00 \\
\hline & D2 & 0 & 23.00 & 0.00 \\
\hline & D3 & 0 & 20.00 & 0.00 \\
\hline & D4 & 0 & 17.00 & 0.00 \\
\hline & D5 & 0 & 14.00 & 0.00 \\
\hline & D6 & 0 & 11.00 & 0.00 \\
\hline & D7 & 0 & 8.00 & 0.00 \\
\hline & D8 & 41 & 5.00 & 205.00 \\
\hline & D9 Dummy & 0 & 0.00 & 0.00 \\
\hline \multirow{9}{*}{ S16 } & D1 & 0 & 28.25 & 0.00 \\
\hline & $\mathrm{D} 2$ & 0 & 25.25 & 0.00 \\
\hline & D3 & 0 & 22.25 & 0.00 \\
\hline & $\mathrm{D} 4$ & 0 & 19.25 & 0.00 \\
\hline & D5 & 0 & 16.25 & 0.00 \\
\hline & D6 & 0 & 13.25 & 0.00 \\
\hline & D7 & 0 & 10.25 & 0.00 \\
\hline & D8 & 2 & 7.255 & 14.50 \\
\hline & D9 Dummy & 18 & 0.00 & 0.00 \\
\hline
\end{tabular}

SUMMARY OF TRANSPORTATION COSTS*

\begin{tabular}{|c|c|c|c|}
\hline $\begin{array}{c}\text { Node } \\
\text { Cost/Unit }\end{array}$ & Supply/Demand & Total Cost & Av. \\
\hline D1 & 39 & 195.00 & 5.00 \\
\hline D2 & 39 & 195.00 & 5.01 \\
\hline D3 & 42 & 211.00 & 5.02 \\
\hline D4 & 43 & 215.00 & 5.02 \\
\hline D5 & 45 & 232.00 & 5.16 \\
\hline D6 & 42 & 212.25 & 5.05 \\
\hline D7 & 45 & 234.00 & 5.20 \\
\hline D8 & 43 & 219.50 & 5.10 \\
\hline
\end{tabular}

*If the result is shown in the transportation table, the optimum demand and capacity analysis can be obtained more clearly: 
International Journal of Managing Value and Supply Chains (IJMVSC) Vol.5, No. 3, September 2014

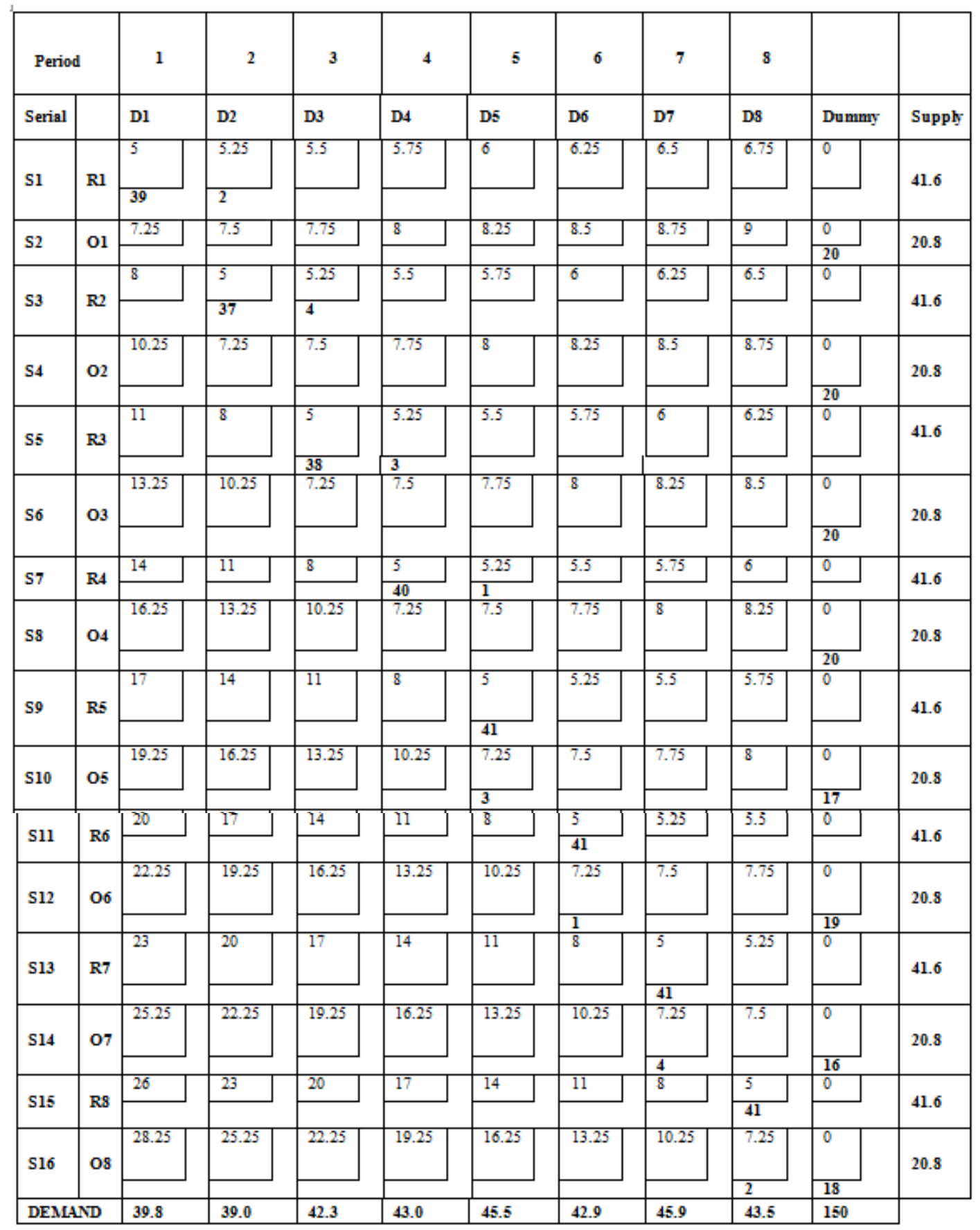

From the result it is observed that though back ordering is allowed, as it includes much greater cost than the regular production cost and overtime production cost, it is not used in the optimum solution table. It is also clear that if the industry follows the aggregate planning process, most of its production can be done in the regular time capacity where the cost is less than the overtime capacity. This will result in a huge amount of reduce in production cost, which ultimately leads to greater profit for the industry 
International Journal of Managing Value and Supply Chains (IJMVSC) Vol.5, No. 3, September 2014

Table 2. Total cost before aggregate planning

\begin{tabular}{|c|c|c|c|c|c|c|}
\hline Period & \multirow{2}{*}{$\begin{array}{c}\text { Deman } \\
\mathrm{d}\end{array}$} & \multicolumn{2}{|c|}{ Supply Capacity } & \multicolumn{3}{|c|}{ Total Cost } \\
\cline { 3 - 7 } & & Regular & $\begin{array}{c}\text { Overtim } \\
\mathrm{e}\end{array}$ & $\begin{array}{c}\text { Cost in } \\
\text { Regular }\end{array}$ & $\begin{array}{c}\text { Cost in } \\
\text { Overtime }\end{array}$ & $\begin{array}{c}\text { Total Cost } \\
\text { (in } \\
\text { thousands) }\end{array}$ \\
\hline 1 & 39.8 & 41.6 & 20.8 & $39.8 * 5=199$ & --------- & 199 \\
\hline 2 & 39.0 & 41.6 & 20.8 & $39 * 5=195$ & --------- & 195 \\
\hline 3 & 42.3 & 41.6 & 20.8 & $41.6 * 5=208$ & $.7 * 7.25=5.075$ & 213.075 \\
\hline 4 & 43.0 & 41.6 & 20.8 & $41.6 * 5=208$ & $\begin{array}{c}1.4 * 7.25=10.1 \\
5\end{array}$ & 218.15 \\
\hline 5 & 45.5 & 41.6 & 20.8 & $41.6 * 5=208$ & $\begin{array}{c}3.9 * 7.25=28.2 \\
75\end{array}$ & 236.275 \\
\hline 6 & 42.9 & 41.6 & 20.8 & $41.6 * 5=208$ & $\begin{array}{c}1.3 * 7.25=9.42 \\
5\end{array}$ & 217.425 \\
\hline 7 & 45.9 & 41.6 & 20.8 & $41.6 * 5=208$ & $\begin{array}{c}4.3 * 7.25=31.1 \\
75\end{array}$ & 239.175 \\
\hline 8 & 43.5 & 41.6 & 20.8 & $41.6 * 5=208$ & $\begin{array}{c}1.9 * 7.25=13.7 \\
75\end{array}$ & 221.775 \\
\hline Total & 341.9 & 332.8 & 166.4 & 1642 & 97.875 & $\mathbf{1 7 3 9 . 8 7 5}$ \\
\hline
\end{tabular}

Table 3. Total cost after aggregate planning

\begin{tabular}{|c|c|c|c|c|c|c|}
\hline Period & Demand & \multicolumn{2}{|c|}{ Supply Capacity } & \multicolumn{2}{l|}{ Total Cost } \\
\cline { 3 - 7 } & & Regular & Overtime & Cost in Regular & $\begin{array}{c}\text { Cost in } \\
\text { Overtime }\end{array}$ & $\begin{array}{l}\text { Total Cost } \\
\text { in } \\
\text { thousands) }\end{array}$ \\
\hline 1 & 39.8 & 41.6 & 20.8 & $39 * 5=195$ & ---------- & 195 \\
\hline 2 & 39.0 & 41.6 & 20.8 & $\begin{array}{c}37 * 5+2 * 5.25=1 \\
95.5\end{array}$ & -------- & 195.5 \\
\hline 3 & 42.3 & 41.6 & 20.8 & $\begin{array}{c}4 * 5.25+38 * 5=2 \\
11\end{array}$ & ---------- & 211 \\
\hline 4 & 43.0 & 41.6 & 20.8 & $\begin{array}{c}4 * 5+2 * 5.25=2 \\
09.5\end{array}$ & --------- & 209.5 \\
\hline 5 & 45.5 & 41.6 & 20.8 & $\begin{array}{c}1 * 5.5+41 * 5=21 \\
0.5\end{array}$ & $7.25 * 3=21.75$ & 232.25 \\
\hline 6 & 42.9 & 41.6 & 20.8 & $41 * 5=205$ & $1 * 7.25=7.25$ & 212.25 \\
\hline 7 & 45.9 & 41.6 & 20.8 & $41 * 5=205$ & $4 * 7.25=29$ & 234 \\
\hline 8 & 43.5 & 41.6 & 20.8 & $41 * 5=205$ & $2 * 7.25=14.5$ & 219.5 \\
\hline Total & 341.9 & 332.8 & 166.4 & 1636.5 & 72.5 & 1499 \\
\hline
\end{tabular}

COST REDUCTION $=(1739.875-1499) / 1739.875=0.1384=13.84 \%$

In the industry's current condition the product is only produced after the order is taken, in this case $4 \%$ of the total production are done in overtime hour which leads to a greater cost. If the aggregate planning procedure is followed in this industry, the net profit of the industry can be increased rapidly. After following the aggregate planning procedure we can reduce the overtime to $2.9 \%$ and we can reduce at least 240 thousand taka per 8 month period.

The total cost of "Bangladesh Cable Shilpa limited, Khulna" cab be reduced up to 240 thousand taka per 8 month period in a year, which contains $13.84 \%$ of the total cost of the industry. 
International Journal of Managing Value and Supply Chains (IJMVSC) Vol.5, No. 3, September 2014

\section{CONCLUSIONS}

In this paper, we studied the aggregate planning of a cable industry using Vogel Approximation Transportation method (VAM).The solution achieved from the TORA software gives the optimum cost or the lowest expense will take place for meeting the demand by present capacity (both the regular time capacity \& overtime capacity) available in the production department. The net profit can be increased in a great amount by applying the aggregate planning model in the cable industry. But the previous order data and the production data have to be reviewed again and again to obtain forecasting demand data. Then it will be closer to the actual order data in the future. The transportation method which we have used in this paper can be used in any aggregate planning problem as it shows the most optimized result of the problem by reducing the cost of production significantly.

\section{REFERENCES}

[1] ROBERT J. THIERAUF, MANAGEMENT SCIENCE: A MODE FORMULATION APPROACH WITH COMPUTER APPLICATIONS, First edition, CBS PUBLISHERS \& Distribution.

[2] HARVEY M. WAGNER, 2nd edition, PRINCIPLES OF OPERATIONS RESEARCH (With Application to Management Decisions). Prentice Hall of India Private Limited, New Delhi.

[3] Barry Render, 8th edition, Quantitative Analysis for Management, Pearson Education, Inc.

[4] MARK D. HANNA, W.ROCKY NEWMAN, Integrated Opertions Management, Prentice Hall of India Private Limited, New Delhi.

[5] Richard B. Chase, F. Robert Jacobs, Nicholas J. Aquilano, Nitin K. Agarwal, 11th edition, Tata McGraw-Hill Publishing Company Limited, New Delhi.

[6] Lynwood A. Johnson, Douglas C. Montgomery, Operations Research in Production Planning, Scheduling, and Inventory Control, JOHN WILEY \& SONS, New York.

[7] John O. McClain, L.Joseph Thomas, Operations Management, Prentice-Hall, Inc., Englewood Cliffs, New Jersey.

[8] BARRY SHORE, Operations Management, Tata McGraw-Hill Publishing Company Limited, New Delhi.

[9] Raymond R. Mayer, Production and Operations Management, 4th edition, McGraw-Hill Book Company.

[10] David M. Miller, J.W. Schmidt, Industrial Engineering and Opertions Research, John Willey \& Sons, Inc.

[11] S.N. Chary, Production and Opertions Management, Tata McGraw-Hill Publishing Company Limited, New Delhi.

[12] James A. F. Stoner, R. Edward Freeman, Daniel R. Gilbert. JR, Management, 6th edition, Dorling Kindersley (India) Pvt. Ltd.

[13] Hamdy A. Taha, Operation Research (An introduction), 8th edition, a sokek.Ghosh publication.

[14] Elwood S. BUFFA, Rakesh K. SARIN, Modern Production/operations Management, 8th edition, John Wiley \& Sons.

[15] R.PANNEERSELVAM, Production and Operations Management, 2nd edition, Prentice Hall of India Private Ltd.

[16] Everett E. ADAM, JR. RONALD J. EBERT, Production \& Operations Management,5th edition, Prentice Hall of India Private Ltd.

[17] Donald R. Lehman, Russell S. Winer, Product Management, 1st edition, Irwin/McGraw-Hill.

[18] Richard B. Chase, Nicholas J. Aquilano, Production \& Operations Management, 3rd edition, Richard DIrwin, INC.

[19] Joseph G. Monks, Operations Management, 2nd edition, McGraw-Hill Book Company.

[20] William J. Stevenson, Operation Management, 8th edition, McGraw-Hill Book Company.

[21] Kostas N. Dervitsiotis, Operation Management, International edition, McGraw-Hill Book Company. 